\title{
Cross plotting of Rock Properties for Fluid and Lithology Discrimination using Well Data in a Niger Delta Oil Field
}

\section{*11BELLO, RASAQ; ${ }^{1}$ IGWENAGU, C. LINDA; ${ }^{2}$ ONIFADE, YS}

\author{
${ }^{I}$ Department of Physics, University of Port Harcourt, Port Harcourt, Nigeria \\ ${ }^{2}$ Department of Physics, Federal University of Petroleum Resources, Effurun, Nigeria
}

\begin{abstract}
The cross plotting of rock properties for fluid and lithology discrimination was carried out in a Niger Delta oil field using well data from a given oil field. The data used for the analysis consist of suites of six wells. The reservoir was evaluated using gamma ray logs, volume of shale, resistivity and neutron porosity for well-02 and well-06. Sand lithology showed low gamma ray, high resistivity and low acoustic impedance. Cross plotting was carried out and the plots with most outstanding results were $\mathrm{Vp} / \mathrm{Vs}$ versus $\mathrm{AI}, \lambda \rho$ Versus $\mathrm{Vp} / \mathrm{Vs}, \mu \rho$ against Density and $\lambda \rho$ versus $\mu \rho$. For the two wells considered, two reservoirs were observed, one reservoir was observed in well - 02 at a depth of $4600 \mathrm{ft}$ to $5050 \mathrm{ft}$.and a reservoir was also observed for well - 06 at a depth of $10240 \mathrm{ft}$ to $10600 \mathrm{ft}$. Crossplotting of rock properties discriminated the wells into lithologies of sand and shale which is typical of Niger Delta. The crossplot also discriminated the fluids into gas, brine and oil. This study has been able to discriminate hydrocarbon reservoirs using well logs in the field of study. ( ) JASEM
\end{abstract}

http://dx.doi.org/10.4314/jasem/v19i3.25

KEYWORDS: Hydrocarbon, Reservoir, Well - Logs, Crossplotting, Lithology

\section{Introduction}

There are many risks associated with the exploitation of hydrocarbons, particularly the potential drilling location and to reduce these risks, it is important to describe a reservoir in terms of its lithology and pore fluid content. This has a direct bearing on reservoir development and its management. Prospecting for reservoir zones in mature fields sometimes requires unconventional exploration tools (Satinder,1998) One successful tool used routinely in the industry to reduce the risk of interpretation is the Amplitude versus Offset or Amplitude Variation with Offset (AVO) analysis which is used as direct hydrocarbon indicator (Ekwe et al, 2012). (AVO) Analysis plays an important role. In modern seismic data interpretation, Amplitude variation with offset It is widely used in hydrocarbon detection, lithology identification, and fluid parameter analysis, due to the fact that seismic amplitudes at the boundaries are affected by the variations of the physical properties just above and just below the boundaries. (Hong and John, 2006). AVO analysis is a technique that geophysicists can execute on seismic data to determine a rock's fluid content, porosity, density or seismic velocity, shear wave information, fluid indicators (hydrocarbon indications). Basically, the AVO method requires three principle applications. Firstly, analysis and interpretation of seismic data named as AVO detection, secondly, sustaining the result obtained from the assessment of seismic data through modeling named as AVO modeling, and, thirdly, a lithological characterization named as inversion of AVO data (Sincer, 2006).

Cross plots are visual representations of the relationship between two or more variables, and they are used to visually identify or detect anomalies which could be interpreted as the presence of hydrocarbon or other fluids and lithologies. Cross plot analysis are carried out to determine the rock properties / attributes that better discriminate the reservoir (Omudu et al., 2007).

Rock physics is usually integrated with AVO analysis for a better understanding of lithology and fluid differentiation. Rock physics creates a link between geophysical observable to geological parameters and nowadays becomes an important part of reservoir characterization (Golyan, 2012). Various rock physics models have their own benefits and limitations. Fluid and lithology discrimination are carried out for reservoir by applying different rock physics templates (RPTs). By plotting acoustic impedance $(\mathrm{AI})$ versus $\mathrm{Vp} / \mathrm{Vs}$ ratio (where $\mathrm{Vp}$ and $\mathrm{Vs}$ are Velocity of primary waves and Velocity of secondary waves respectively), data points concentrate within a narrow zone indicating high AI and $\mathrm{Vp} / \mathrm{Vs}$ ratio suggest that application of rock 
physics template in the study area needs significant modification compared to generalized RPTs. As typically used in the oil and gas industry, the term rock physics is usually applied to the measurement, modeling, and interpretation of elastic wave propagation in sedimentary rocks (Golyan, 2012).

\section{MATERIALS AND METHOD}

This section presents a procedure used to evaluate petrophysical properties from wireline log data and surface seismic data. Our approach to discriminate between fluids and lithologies from well $\log$ and seismic data include four major steps: well-log editing and modelling, well log cross-plotting, seismic modeling and attribute generation from seismic data using model-based inversion.

\section{Data Collection}

Table 3.1: Table showing the available logs in the six wells used in this study

\begin{tabular}{lll}
\hline WELLS & $\begin{array}{l}\text { DEPTH } \\
\text { REGISTRATION }\end{array}$ & \multicolumn{1}{c}{ AVAILABLE LOGS } \\
\hline Well-01 & $308 \mathrm{ft}-13019 \mathrm{ft}$ & CALI, GR, LITH, LLD, PHIE, PHI_SNS, SP, SW, SWARCH, VSH, VSHSTB, checkshot data \\
Well-02 & $46 \mathrm{ft}-12996 \mathrm{ft}$ & DT, GR, LITH, LLS, RES, SP, VSH. \\
Well-03 & $51 \mathrm{ft}-13000 \mathrm{ft}$ & CALI, DRHO, DTU, GR, LITH, LLS, MSFL, NPHI, PHIE, PHI_SNS, RES, RHOB, SP, SW, \\
& & SWARCH, VSH, VSHSTB, and deviation survey. \\
Well-04 & $10 \mathrm{ft}-11541.50 \mathrm{ft}$ & CALI, CILD, DT, DTL, GR, LITH, LLD, LLS, NPHI, PHIE, RHOB, SGR, SP, SW, VSH \\
Well-05 & $3849 \mathrm{ft}-11675 \mathrm{ft}$ & CALI, DT, DTL, GR, LITH, LLD, LLS, MSFL, NPHI, PHIE, RHOB, RT, SGR, SP, SW, VSH \\
Well-06 & $2800 \mathrm{ft}-13089 \mathrm{ft}$ & CALI, GR, HDRS, HMRS, LITH, NPHI, PHIE, RES, RHOB, SP, SW, VSH and deviation survey. \\
\hline
\end{tabular}

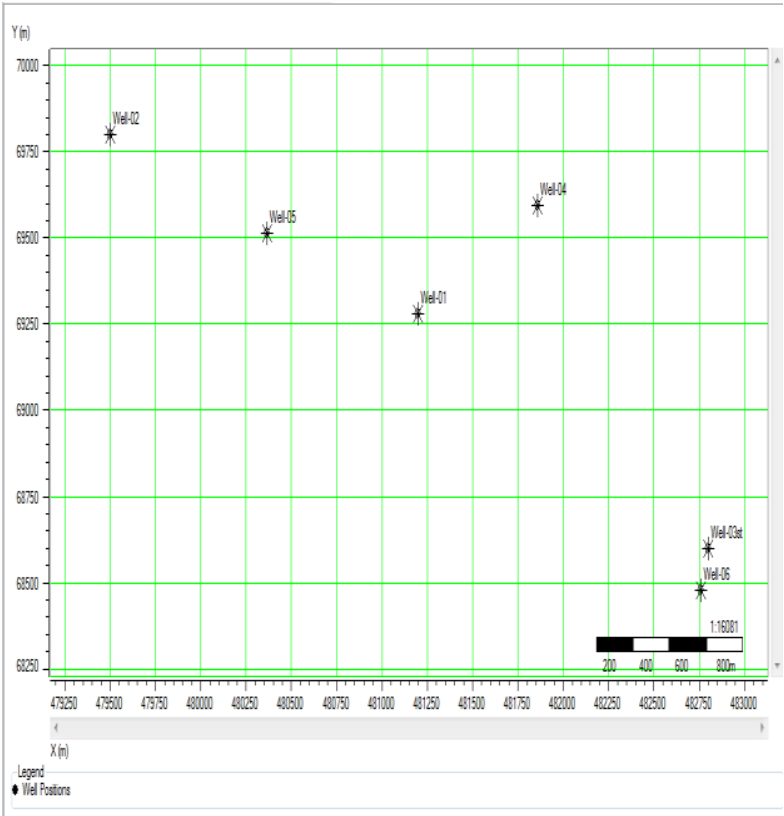

Fig 1: The base map of the study area. Wells are situated in the Northern and south-eastern region of the field.
The data used in this thesis include well log data, check-shot surveys, directional surveys and biostratigraphy information from a Niger Delta field provided by Chevron Nigeria Ltd. The data consists of suites of six wells (01, 02, 03, 04, 05 and 06) and its seismic sections. The analysis was done using Hampson Russell Software (HRS). The well log data was evaluated and rock attribute cross-sections were created.

Well Log Data: The collection of wireline log data includes sonic $\log$, density $\log$, resistivity $\log$, calliper $\log$, porosity $\log$, shale volumetric $\log$ and gamma ray log as shown in table 1 and figures 1 to 8 . The zone of interest is typically a sand/shale/sand sequence. The wells are situated in the northern and south-eastern region of the field as shown in figures 1 and 2 and are used for the crossplot and statistical analysis.

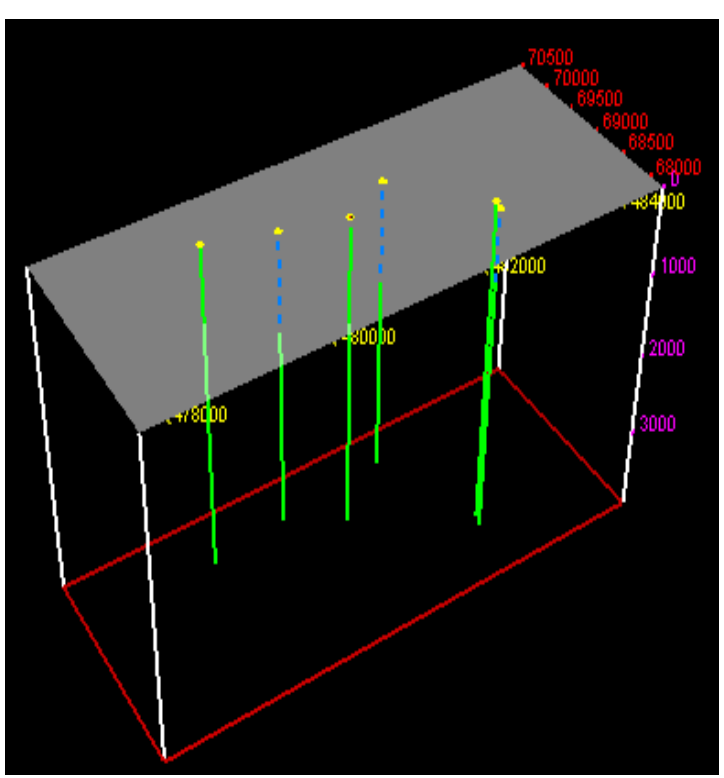

Fig 2: 3D view of the well in the study area 


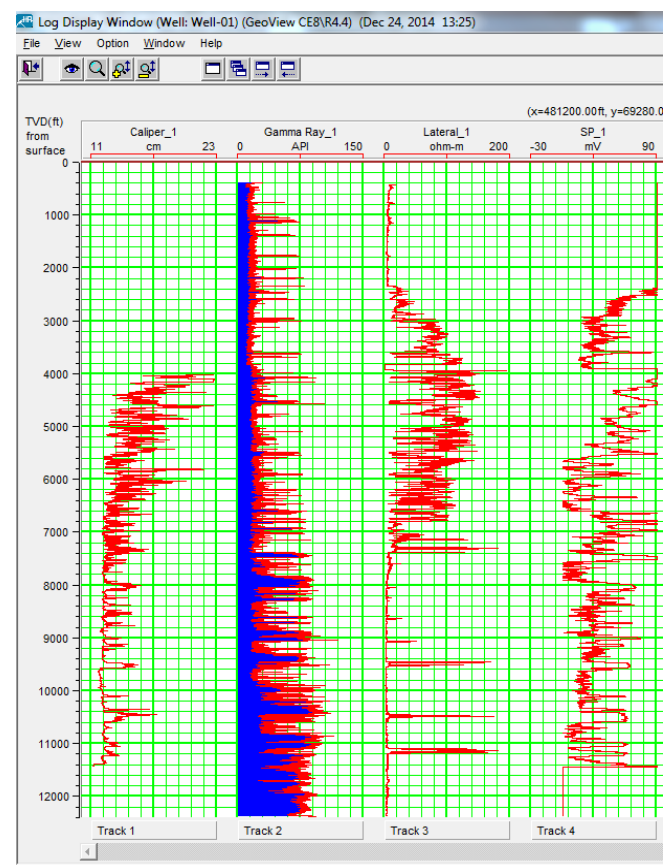

Fig 3: Wireline log data for Well-01 showing suite of logs (RED COLOUR)

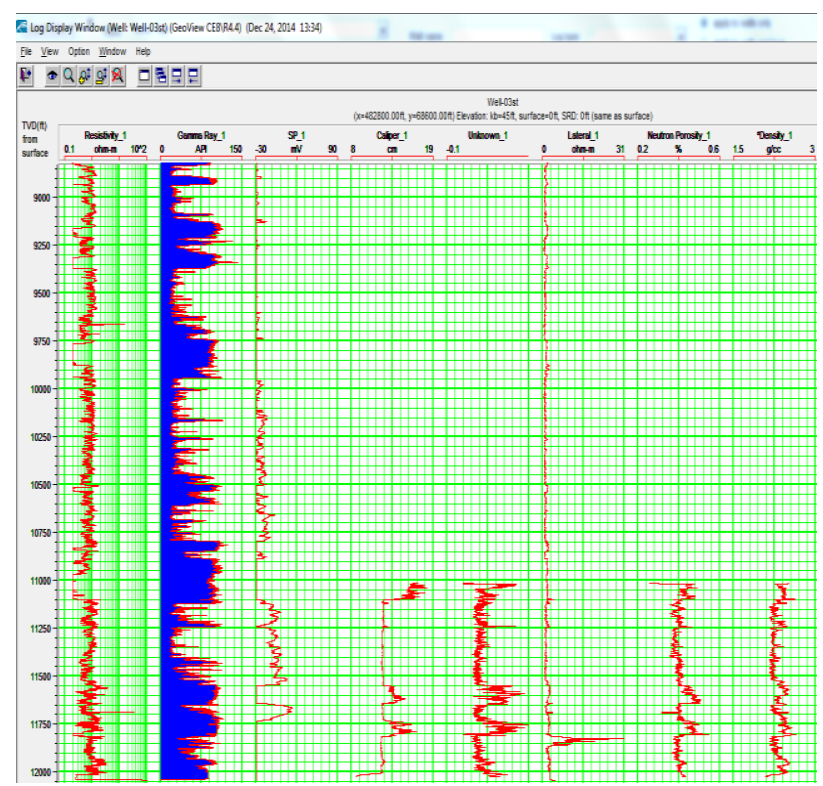

Fig 5: Wireline log data for Well-03 showing suite of $\operatorname{logs}$

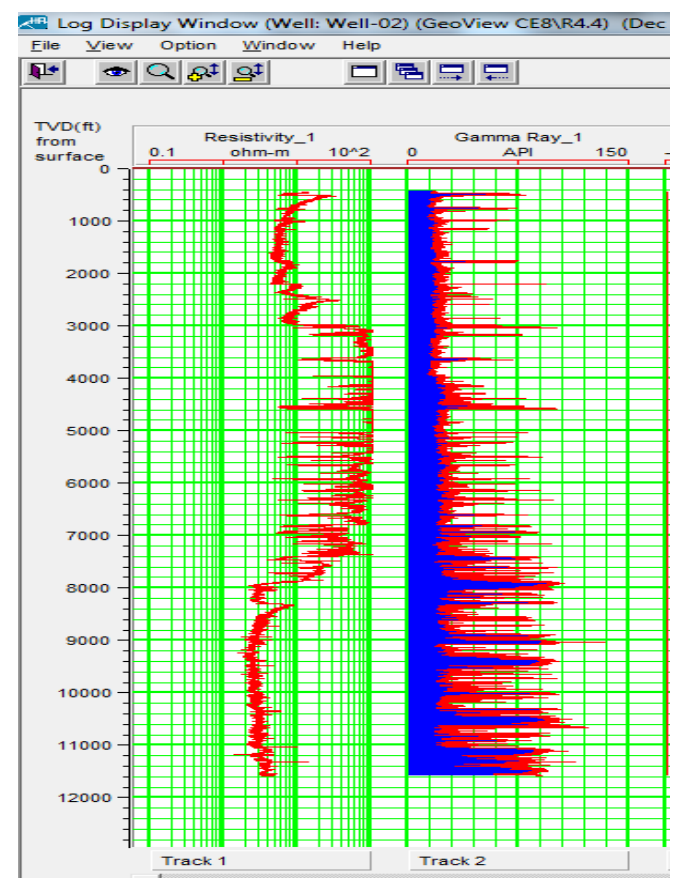

Fig 4: Wireline log data for Well-02 showing suite of $\operatorname{logs}$

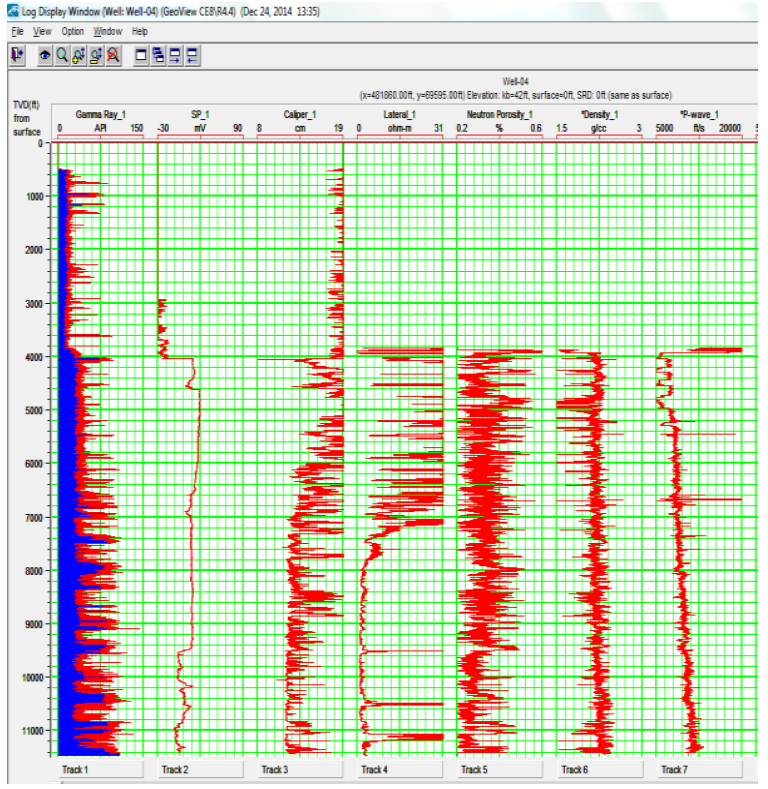

Fig 6: Wireline log data for Well-04 showing suite of logs (GR, SP, Caliper, Lateral, Neutron Porosity, Density and P-Wave 


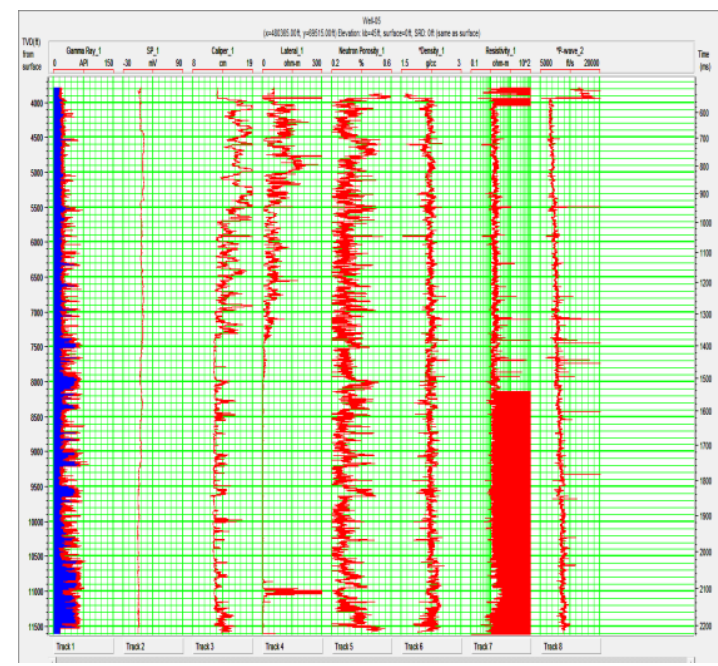

Fig 7 Wireline log data for Well-05 showing suite of $\log s$

Geophysical Tool/ Technology (Hampson Russell Software): Hampson Russell Software was used for the analysis of this work. It consists of quite a number of modules, some of which include the Geoview which serves as a starting point of any Hampson Russell program. Well log data are loaded into Geoview well database through the Well Explorer.

The E $\log$ is the well log editing and modelling tool embedded within the Hampson-Russel software suite of applications. It is started from Geoview and used to edit and average logs. Cross plots are also made here and zones of interest defined on the cross plots that can be projected back onto the input logs to visualize its equivalent depth.

\section{Methodology}

The main workflow carried out in this work include: well-log editing and modelling and well log crossvelocity.

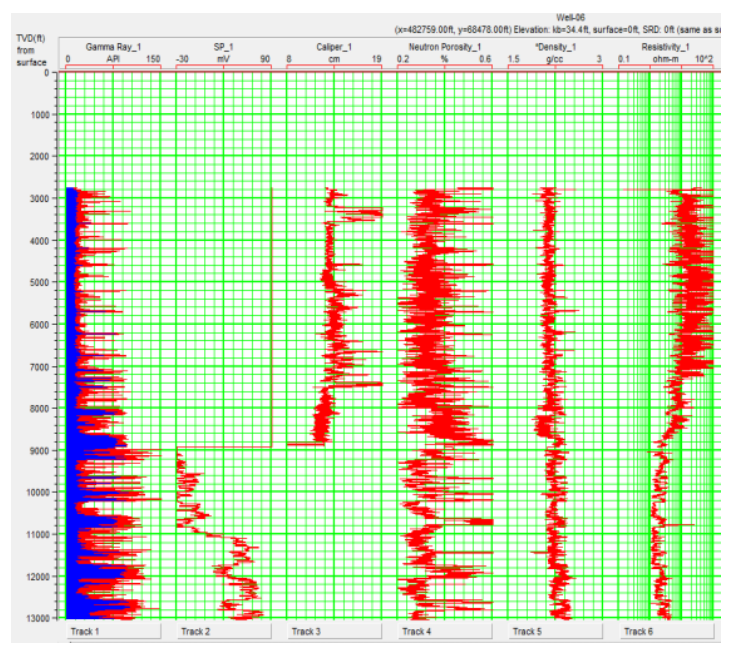

Fig 8: Wireline log data for Well-06 showing suite of $\operatorname{logs}$

plotting. Using rock physics algorithm, rock attributes which includes lambda-rho, mu-rho and Poisson-impedance rock property volumes were extracted from the well data. The crossplot analysis was carried out to determine fluid and lithology response of the rocks.

After data importation, a log editing and conditioning were carried out. The log editing operations applied in this work include mainly checkshot correction and median filtering.

A check shot correlation was carried out (figure 9) which modifies the depth-time curve associated with a sonic $\log$ in order to improve the tie between a synthetic and real seismic data. This is necessary because the program extrapolates the first $\mathrm{Vp}$ value to the surface, which usually overestimates the near surface

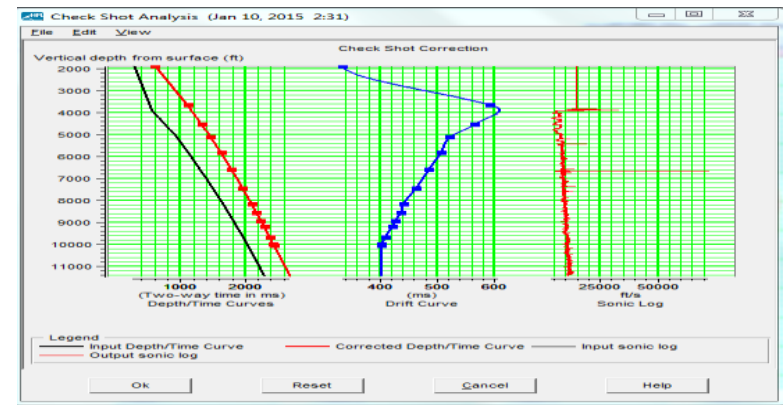

Fig 9: Checkshot correction applied to sonic log data.

The sonic curves at the far left show the original curve in red and the effect of the correction, shown in black. 
Well Log Attribute - Crossplot Analysis: Cross plots are visual representations of the relationship between two or more variables, and they are used to visually identify or detect anomalies which could be interpreted as the presence of hydrocarbon or other fluids and lithologies. Cross plot analysis are carried out to determine the rock properties / attributes that better discriminate the reservoir (Omudu etal, 2007).

The goal of this rock physics analysis is to determine the feasibility of discriminating between reservoir facies and imaging architecture using seismic attributes. Several crossplots shall be done, but the ones with the most significant discriminating power between litho-fluid facies shall be used for analysis.

A typical crossplots that shall be done in this work is the crossplot of $V_{\mathrm{p}} / V_{\mathrm{s}}$ Ratio against Acoustic Impedance (Zp). This crossplot shows fluid as well as lithology discrimination along the acoustic impedance axis. It describes the conditions in terms of lithology and fluid content than $V_{\mathrm{P}} / V_{\mathrm{S}}$ ratio. P-impedance and $V_{\mathrm{P}} / V_{\mathrm{S}}$ ratio relationship discriminate both fluid and lithology. The $V_{\mathrm{P}} / V_{\mathrm{S}}$ ratio is a fluid indicator because compressional waves are sensitive to fluid changes, whereas shear waves are not except in the special case of very viscous oil. P-impedance shows a better discrimination which can better describe the reservoir conditions in terms of lithology and fluid content than the $V_{\mathrm{P}} / V_{\mathrm{S}}$ ratio.

Acoustic impedance (or product of velocity and density) and Poisson's ratio (or ratio $V_{\mathrm{P}} / V_{\mathrm{S}}$ ) contrast can show the position of gas-sand, water-sand and shale in a $V_{\mathrm{P}} / V_{\mathrm{S}}$ versus impedance crossplot.

Well - Log Rock attribute Estimation: In this stage, rock attributes were estimated from the input log data using rock-physics algorithms created in HAMPSON RUSSELL eLOG tool. These attributes include shear wave velocity from Castagna's equation, $\mathrm{Vp} / \mathrm{Vs}$ ratio and acoustic impedance. Acoustic impedance is the product of p-wave velocity and density. Castagna et al. (1985) have given empirical relations from estimating Vs from $\mathrm{Vp}$ in multimineral, brine-saturated rocks based on empirical, polynomial $\mathrm{Vp}-\mathrm{Vs}$ relations in pure monomineralic lithology (Castagna et al., 1993). The polynomial regression coefficient given by Castagna et al., (1993) for pure monomineraliclithologies is given as

$$
V_{s}=a_{i 2} V_{p}^{2}+a_{i 1} V_{p}+a_{i 0}
$$

by high porosities. where $a_{i j}$ is the empirical regression coefficients, Vp and Vs are the P- and S-wave velocities.

Simple combination of the Vp, Vs and density rock properties were used in the generation of the attributes. Goodway et al., (1997) proposed the lambda-mu-rho technique which has its origin in the hard rock exploration areas of Canada. The lambda-rho is given as

$$
\lambda \rho=\left(\rho V_{p}\right)^{2}-c\left(\rho V_{s}\right)^{2}
$$

where $V p, V s$, and $\rho$ are the compressional velocity, shear velocity and density and $\mathrm{c}=2$. Russell et al., (2003) observed that with availability of well log data, 'c' could be determined locally. The constant, c, influences the fluid component computation which varies for different geologic environment. The value of c for both offshore and onshore falls within the range obtained by Dillon et al., (2003). The Murho technique is simply the square of the $\mathrm{S}$-wave impedance and represents rigidity (solid component) $\mu \rho=\left(\rho V_{s}\right)^{2}$

\section{RESULTS AND DISCUSSION}

This section shows results from cross plots. The cross plots analyses are useful in differentiating between fluid and lithologies in the reservoir (Omudu et al., 2007). Cross plotting is widely used in AVO analysis, because it facilitates the simultaneous and meaningful evaluation of two attributes. Cross plotting appropriate pairs of attributes so that common lithologies and fluid types generally cluster together allows for straightforward interpretation.

Reservoir Evaluation Using Logs: The well curves used for the analysis are shown in Figure 10 and Figure 11. The logs include caliper, gamma ray, shale volume and resistivity for well-02 and well-06. These wells were chosen among the six wells because they contain some useful suite of logs. The wells exhibit a dominantly shale/sand/shale sequence typical of the Niger Delta formation. The wells were analysed in terms of fluid type and lithology. Shale lithologies were delineated by the high gamma ray value. Shale lithologies cause the deflection of resistivity to the far left due to its high conductive nature. Regions showing low gamma ray, high resistivity, and low acoustic impedance are mapped as sand lithologies. Sand lithologies showing very low acoustic impedance and high resistivity are regions of high hydrocarbon saturation. In well-06, the REV-01 reservoir is characterised 


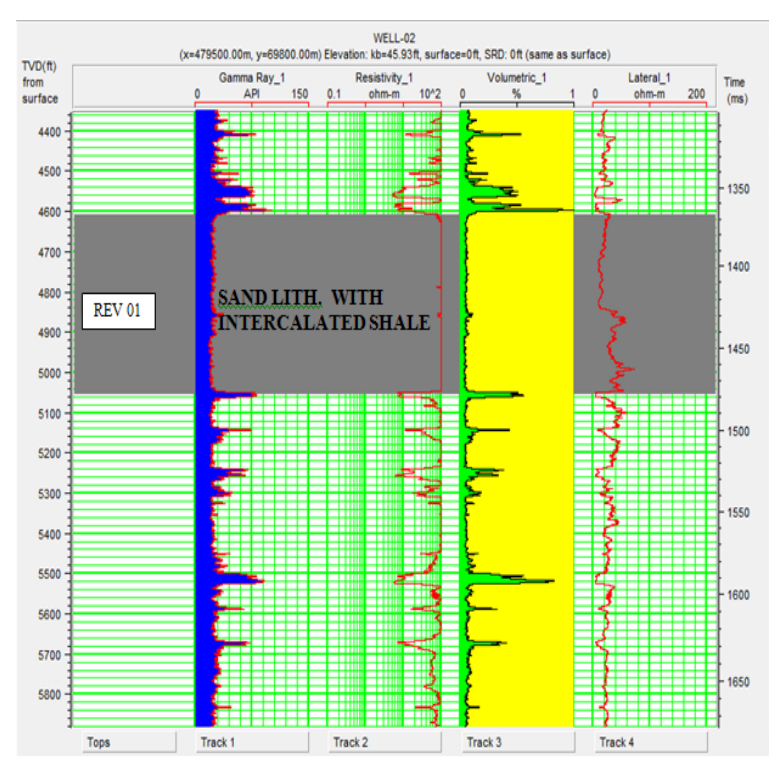

Fig 10: Well-02 showing the suites of Logs used in the analysis; Gamma ray, Resistivity Shale volume,

$V p / V_{S}$ Ratio against Acoustic Impedance: The cross plot of $\mathrm{Vp} / \mathrm{Vs}$ ratio against Acoustic impedance $\left(\mathrm{Z}_{\mathrm{p}}\right)$ (Figure 12), distinguishes the REV-01 reservoir into three zones namely; hydrocarbon zone (red ellipse), brine zone (yellow ellipse) and shale zone (blue ellipse). This crossplot shows better fluid as well as

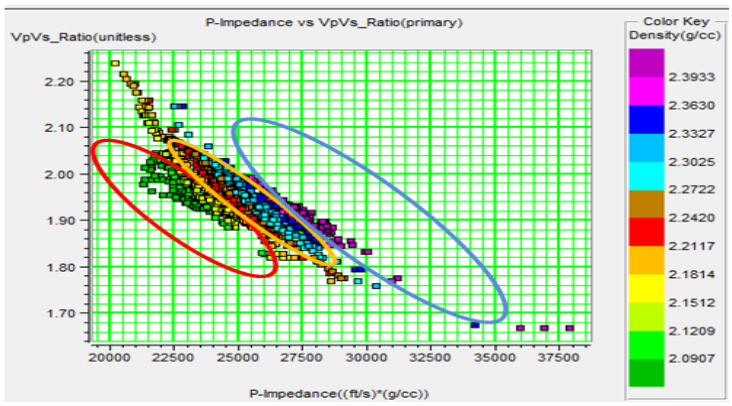

Fig 12: Crossplot of $\mathrm{Vp} / \mathrm{Vs}$ ratio vs. Acoustic impedance

Lambda-Rho (Incompressibility) against Vp/Vs: Figure 13 shows the variation of lambda-Rho (incompressibility) against $\mathrm{Vp} / \mathrm{Vs}$ for sands and shale/sand/shale sequences. The plots are better aligned towards the lambda rho axis, thus making lambda rho a better lithology discrimination tool. The black ellipse describes shale zone, the yellow describes brine sand, the red ellipse describes hydrocarbon sand and the blue describes gas zone.

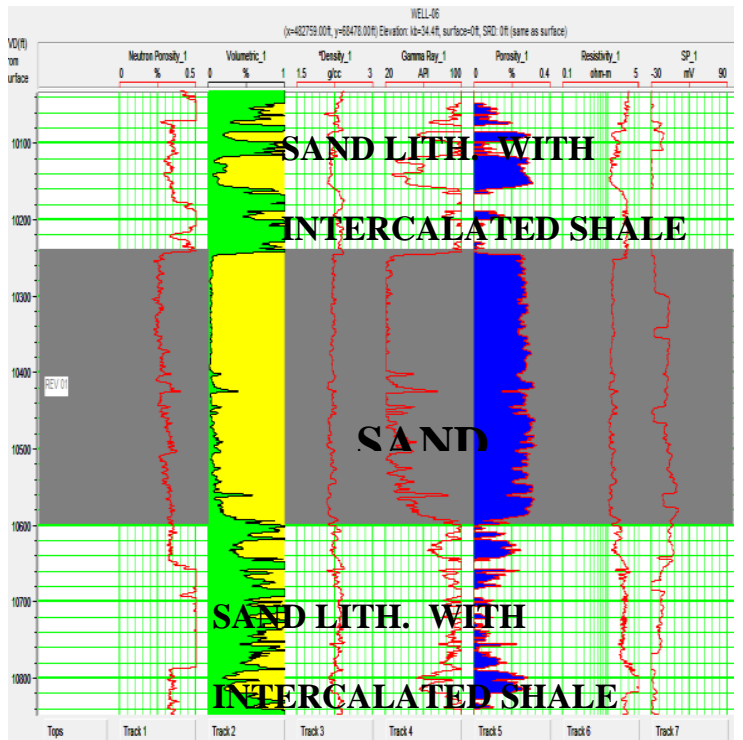

Fig 11: Well-06 and suite of Logs used in the analysis: Neutron Porosity, Volumetric, Density, Gamma ray, Porosity Resistivity and SP logs.

lithology discrimination along the acoustic impedance axis, indicating that acoustic impedance attribute will better describe the REV-01 reservoir conditions in terms of lithology and fluid content than $\mathrm{Vp} / \mathrm{Vs}$ ratio.

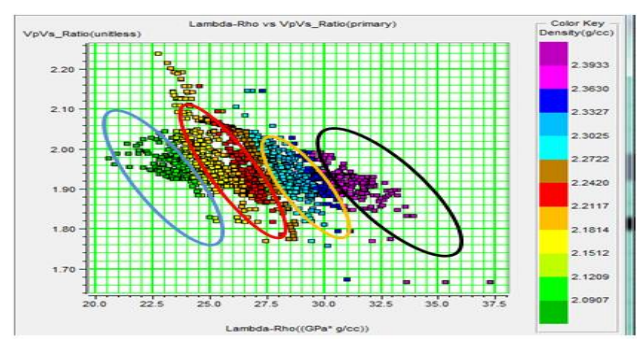

Fig 13: Cross plot of Lambda-Rho against Vp/Vs

MU-RHO against Density: In the cross plot of $\mathrm{Mu}$ rho against density, both mu rho and density are lithology discriminators, with density also being a fluid discriminator. $\mathrm{Mu}$ rho values are high for sand and low for shale. Conversely, the density of shale is higher than that of sand. Furthermore, brine is denser than hydrocarbon (oil and gas). Thus, the blue ellipse in the figure 14 indicates hydrocarbon bearing sand, the yellow ellipse shows the brine saturated region, while the black section describes the shale region. 


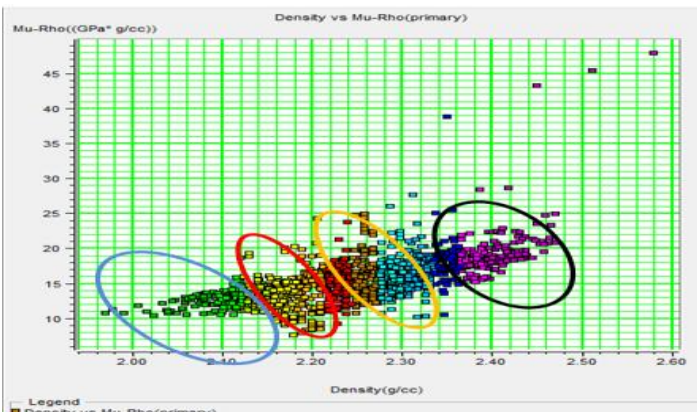

Fig 14: Cross Plot of Mu-Rho against Density
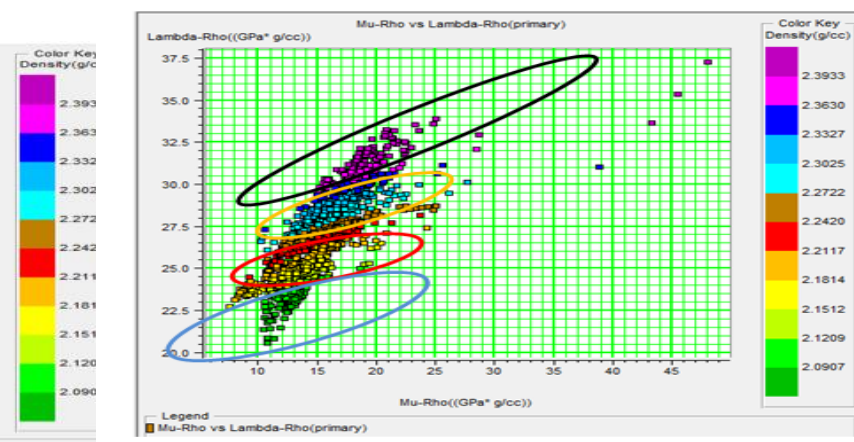

Fig 15: Cross plots of lamdarho $(\lambda \rho)$ against murho $(\mu \rho)$
Lambda-Rho (Incompressibility) Against Mu-Rho : Cross plots of lamdarho $(\lambda \rho)$ against murho $(\mu \rho)$ in figure 15, shows separation into four zones that can be inferred to be probable shale (black eclipse), brine (yellow eclipse), oil (red eclipse) and gas zone (blue eclipse) confirmed by lowest density values. The plot indicates that $\lambda \rho$ is more robust than $\mu \rho$ in the analysis of fluids in the field of study, and that $\mu \rho$ values are relatively low for the reservoir sand.

Well data for six suits of wells were used. The data was loaded into the Hampson Russel software (HRS). Wells -02 and well-06 having more well logs were used in the analysis. Reservoir evaluation was carried out on the wells so as to determine the reservoir in the wells. The reservoirs were mapped out in the given well. Log transforms were done in which rock attributes that were not existing were generated using the E log in the HRS.

Cross plotting of some selected rock properties and rock attributes were carried out and the following results were obtained. First, Vp/Vs ratio against Acoustic impedance distinguishes the REV-01 reservoir into hydrocarbon zone, brine zone and shale zone. Second, lambda rho (incompressibility) against $\mathrm{Vp} / \mathrm{Vs}$ discriminates the reservoir of interest in sands and shale/sand/shale sequences. Next was the Mu rho against density. It was observed that both mu rho and density are lithology discriminators, with density also being a fluid discriminator. Mu rho values are high for sand and low for shale. Conversely, the density of shale is higher than that of sand. Finally, cross plots of lambda-rho $(\lambda \rho)$ against mu-rho $(\mu \rho)$ shows separation into four zones that can be inferred to be probable shale, brine and gas zone confirmed by lowest density values.

Conclusion: For a successful exploration and production of hydrocarbons, it is imperative to characterise the hydrocarbon reservoir accurately in terms of its fluid properties and lithology. Hence, good knowledge of petrophysical parameters must be known to understand the lithology and fluid content.
The Acoustic impedance (Zp), Lambda-rho $(\lambda \rho)$, Murho $(\mu \rho)$, and Poisson impedance (PI) attributes were found to be most robust in lithology and fluid discrimination within the reservoir in the crossplot analysisThe $\lambda-\mu-\rho$ technique was able to identify gas sands, because of the separation in responses of both the $\lambda \rho$ and $\mu \rho$ sections to gas sands versus shale. Many different lithologies could also be identified by the crossplot of $\lambda \rho$ versus $\mu \rho$. This is possible because each lithology has a different rock properties response subject to fluid content and mineral properties.

\section{REFERENCES}

Castagna, J.P., Batzle, M.L., and Eastwood, R.L., (1985). Relationship between compressionalwave and shear-wave velocities in clastic silicate rocks, Geophysics, Vol. 50, p. 571-581.

Castagna, J. P.,M. L. Batzle, and T. K. Kan, (1993), Rock physics-The link between rock properties and AVO response, in J. P. Castagna and M. M. Backus, eds., Offset-dependent reflectivity: Theory and practice of AVO analysis: SEG, 135171.

Dillon, L., Schwedersky, G., Vasquez, G., Velloso, R., and Nunes, C., (2003), A multiscale DHI elastic attributes evaluation: The Leading Edge, 22, 1024-1029.

Ekwe A. C., K.M. Onuoha and N. Osayande, (2012), Fluid and Lithology Discrimination Using Rock Physics Modelling and Lambda-mu-rho Inversion: An Example from Onshore Niger Delta, Nigeria: Search and Discovery Article \#40865

Golyan.M.,F.,2012,Compaction rock property evolution and rock physics diagnostics of

Askeladddiscovery,Norwegian Barents Sea.Retrieved from http://urn.nb.no/URN:NBN:no-32607

Goodway, B., Chen, T., and Downton, J., (1997) Improved AVO fluid detection and lithology 
discrimination using Lame petrophysical parameters; $\lambda \rho, \mu \rho \& \lambda \rho / \mu \rho$ fluid stack, from Pand $S$ inversions: Presented at the 67th Annual International Meeting, SEG, Expanded Abstracts, $183-.186$.

Hong. F., and John.c., (2006),AVO

principles,processing and inversion,CREWES Research report,Volume8.

Omudu, M. L. and J. O. Ebeniro, S. Olotu.,( 2007), Optimizing Quantitative Interpretation for Reservoir Characterization: Case Study Onshore Niger Delta: A paper presented at the $31^{\text {st }}$ Annual SPE International Technical Conference and Exhibition in Abuja, Nigeria.
Russell, B.H., Hedlin, K., Hilterman, F.J., and Lines, L.R., (2003), Fluid-property discrimination with AVO: A Biot-Gassmann perspective: Geophysics, 68, 29-39.

Satinder,C., (1998),Multi Attribute Seismic Analysis on AVO derived parameters- a case studt.Core lab reservior Technologies, Calgary, AB.

Sincer,I.,(2006),Seismic acquisition proposal and design parameters, estimation bulletin of Turkish TAPG Bulletin,Volume18,No.1,page 39-56. 